\title{
Estimating daily global solar radiation by day of year in China
}

\author{
Huashan $\mathrm{Li}^{*}$, Weibin Ma, Yongwang Lian, Xianlong Wang \\ Key Laboratory of Renewable Energy and Gas Hydrate, Guangzhou Institute of Energy Conversion, Chinese Academy of Sciences, No. 2 Nengyuan Road, Wushan, Tianhe, \\ Guangzhou 510640, China
}

\section{A R T I C L E I N F O}

\section{Article history:}

Received 26 January 2010

Received in revised form 29 March 2010

Accepted 29 March 2010

Available online 18 April 2010

\section{Keywords:}

Global solar radiation

Empirical model

Statistical error test

China

\begin{abstract}
A B S T R A C T
In this study, a new empirical model is proposed for estimating daily global solar radiation on a horizontal surface by the day of the year. The performance of the proposed model is validated by comparing with three trigonometric correlations at nine representative stations of China using statistical error tests such as the mean absolute percentage error (MAPE), mean absolute bias error (MABE), root mean square error (RMSE) and correlation coefficients $(r)$. The results show that the new model provides better estimation and has good adaptability to highly variable weather conditions. Then the application of the methodology is performed for the other 70 meteorological stations across China.
\end{abstract}

(c) 2010 Elsevier Ltd. All rights reserved.

\section{Introduction}

Solar energy is one of the most important and promising renewable and sustainable energy. China has abundant solar energy resources and more than two-thirds of areas receive an annual total solar radiation that exceeds $5.9 \mathrm{GJ} / \mathrm{m}^{2}$ with sunshine duration more than $2200 \mathrm{~h}$ [1]. It is meaningful to substitute solar energy for fossil energy with respect to solar energy resources.

An accurate knowledge of the solar radiation data at a particular geographical location is important for solar energy system design [2]. However, in most areas of the world, solar radiation measurements are not easily available due to cost and techniques involved. There are only 103 solar radiation observation stations until 2008 in Chinese mainland [3]. Long-term data on global solar radiation are not available for most areas in China, especially in remote rural and mountainous areas, where approximately $80 \%$ of the Chinese population is living [4]. Therefore, elaborating methods to estimate the solar radiation is of great significance.

Solar radiation can be estimated by means of empirical relations using other available meteorological observations [5-17], interpolating methods [18], geostationary satellite images [19], time series methods [20], stochastic weather models [21], physically radiative transfer models [22], and the artificial neural network method $[23,24]$. Among the numerous methods, those based on empirical correlations using commonly measured meteorological data are attractive due to lower data requirement and computation cost [10]. Recently, several empirical formulas using

\footnotetext{
* Corresponding author. Tel.: +86 20 87057792; fax: +86 2087057791 .

E-mail address: lihs@ms.giec.ac.cn (H. Li).
}

some available meteorological parameters have been tested around the world. The meteorological parameters include sunshine hours [5-8], ambient temperature [9-11], cloudiness [1214], relative humidity [15], precipitation [16] and vapor pressure [17].

In general, although sophisticatedly empirical formulas try to simulate solar radiation with a good prediction, it is on the other hand, very useful to build reliable and easy models to estimate solar radiation.

Simple models to estimate solar radiation without meteorological data have been implemented by using the only one parameter, i.e., the day of the year [25-28]. Bulut [25] developed a model to estimate the daily global solar radiation for Istanbul using longterm measured data with a sine wave equation. Subsequently, Bulut and Büyükalaca [26] tested the model for 68 locations in Turkey and the results showed that the predictions from the model agree well with the long-term measured data. Al-Salaymeh [27] predicted the daily global solar radiation of Amman city in Jordan on a horizontal oriented surface using four models, including a sine wave model. Statistical results showed that the sine wave model gave best fit. Kaplanis and Kaplani [28] used a cosine wave model to calculate the daily global solar radiation in six climatic zones of Greece and the correlation coefficient for all cases is higher than 0.996 .

The main advantage of these models is the readily usage of mathematical expressions even by a pocket calculator and thus, do not require tedious inputting work for the variables and database files for simulation [25]. However, there has been a lack of reports in literature about the evaluation of the applicability of these models for estimating daily global solar radiation. 
In the present study, a new trigonometric model in conjunction with a sine and cosine wave for estimating the daily global radiation is proposed. The performance of the proposed model is validated by comparing with three existing trigonometric correlations at nine representative stations of China using statistical error tests, and then the methodology is applied to the other 70 meteorological stations across China.

\section{Data and methodology}

\subsection{Data}

Daily measured global solar radiation data of 79 meteorological stations covering all over China are taken from the National Meteorological Information Centre (NMIC), China Meteorological Administration and then are averaged to obtain the annual mean values after processing. There are missing measurements in the data, and they are marked and coded as 32766 in the files. Fig. 1 shows the distribution of the selected stations. The daily global solar radiation data measured during at least 10 years between January 11994 and December 312008 are used in the calculations.

The quality control of the original solar radiation data is performed to eliminate spurious data and inaccurate measurements, with the clearness index $K_{t}$ as an indicator. Data will be rejected if the daily global solar radiation were greater than the corresponding extraterrestrial radiation, i.e., $K_{t}>1$, or the daily global solar radiation were less than a minimum value expected with continuous overcast conditions. The smallest acceptable value for $K_{t}$ is set as 0.015 , representing a heavy overcast sky for the whole day [29-31]. All excluded and missing data, accounting for approximately $0.58 \%$ of the whole data-base, are replaced with the values derived from those of preceding and subsequent days by interpolation.

\subsection{Methods}

Daily solar radiation is a quasi-periodic phenomenon on a yearly cycle due to seasonal effects [32]. It is convenient to model daily global solar radiation by the day of the year. Among the models estimating daily global solar radiation by the day of the year, trigonometric correlations give excellent fitting. A brief description of the trigonometric models examined is given below.

Bulut [25] proposed a sine wave model:

$H=a_{0}+a_{1} \times\left|\sin \left[\frac{\pi}{365}(n+5)\right]\right|^{1.5}$

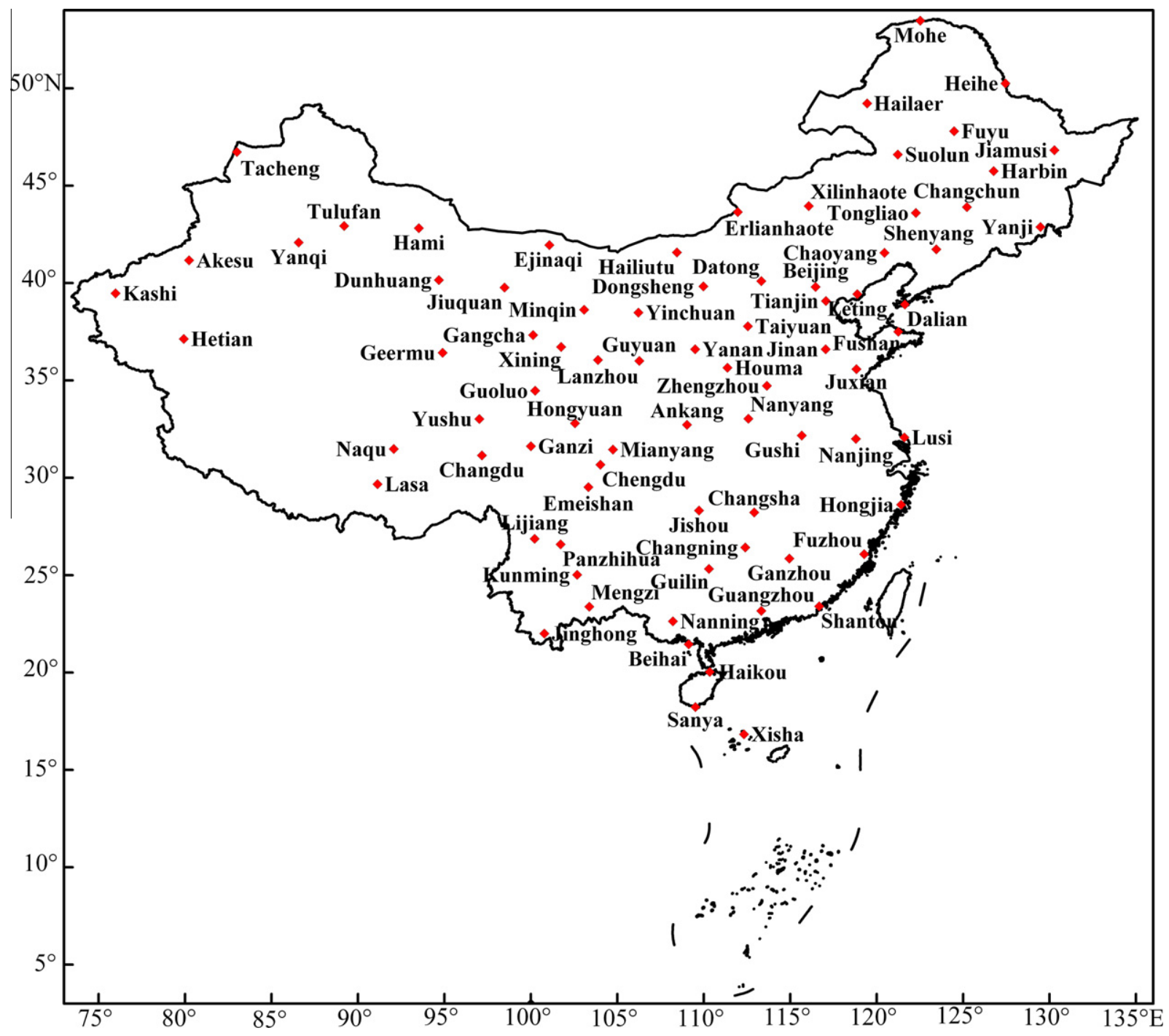

Fig. 1. Distribution of the selected stations in China. 
Table 1

Regression coefficients of Eqs. (1)-(4) and errors at nine representative stations.

\begin{tabular}{|c|c|c|c|c|c|c|c|c|c|c|c|c|c|}
\hline \# & Location & Model \# & $a_{0}$ & $a_{1}$ & $a_{2}$ & $a_{3}$ & $a_{4}$ & $a_{5}$ & $a_{6}$ & MAPE & MABE & RMSE & $r$ \\
\hline \multirow[t]{4}{*}{1} & Minqin & 1 & 8.644 & 15.372 & - & - & - & - & - & 6.616 & 1.163 & 1.566 & 0.958 \\
\hline & & 2 & 16.847 & -7.640 & -382.281 & 1.978 & - & - & - & 5.545 & 0.980 & 1.314 & 0.970 \\
\hline & & 3 & 17.217 & -7.449 & -6.047 & - & - & - & - & 5.932 & 1.018 & 1.330 & 0.970 \\
\hline & & 4 & 16.440 & -7.889 & 0.909 & 8.360 & 0.519 & 1.946 & 7.915 & 5.254 & 0.936 & 1.273 & 0.972 \\
\hline \multirow[t]{4}{*}{2} & Shantou & 1 & 10.463 & 6.845 & - & - & - & - & - & 12.892 & 1.720 & 2.100 & 0.741 \\
\hline & & 2 & 14.329 & -3.798 & 359.014 & 1.065 & - & - & - & 8.845 & 1.205 & 1.582 & 0.863 \\
\hline & & 3 & 14.282 & -3.813 & -0.456 & - & - & - & - & 8.852 & 1.206 & 1.583 & 0.863 \\
\hline & & 4 & 14.273 & -3.835 & 1.002 & 1.115 & -0.603 & 4.353 & 0.597 & 8.594 & 1.168 & 1.526 & 0.873 \\
\hline \multirow[t]{4}{*}{3} & Leting & 1 & 6.743 & 13.081 & - & - & - & - & - & 9.625 & 1.344 & 1.795 & 0.927 \\
\hline & & 2 & 12.816 & -7.119 & -431.305 & 0.847 & - & - & - & 8.156 & 1.136 & 1.558 & 0.945 \\
\hline & & 3 & 14.038 & -6.341 & 0.294 & - & - & - & - & 9.512 & 1.263 & 1.65 & 0.939 \\
\hline & & 4 & 13.755 & -1.037 & 2.257 & 0.270 & -6.327 & 0.943 & 0.482 & 7.630 & 1.069 & 1.418 & 0.955 \\
\hline \multirow[t]{4}{*}{4} & Harbin & 1 & 4.021 & 15.973 & - & - & - & - & - & 9.095 & 1.152 & 1.550 & 0.961 \\
\hline & & 2 & 11.886 & -8.315 & 411.802 & 2.119 & - & - & - & 7.857 & 0.994 & 1.388 & 0.969 \\
\hline & & 3 & 12.929 & -7.678 & 0.214 & - & - & - & - & 9.267 & 1.098 & 1.466 & 0.965 \\
\hline & & 4 & 11.607 & 8.509 & 0.861 & 5.337 & 0.739 & 3.877 & -4.615 & 7.003 & 0.913 & 1.286 & 0.974 \\
\hline \multirow[t]{4}{*}{5} & Ganzhou & 1 & 6.411 & 10.938 & - & - & - & - & - & 19.393 & 2.033 & 2.481 & 0.831 \\
\hline & & 2 & 12.782 & -5.699 & -345.566 & 2.087 & - & - & - & 12.983 & 1.394 & 1.751 & 0.920 \\
\hline & & 3 & 12.512 & -5.787 & -0.336 & - & - & - & - & 13.053 & 1.411 & 1.763 & 0.919 \\
\hline & & 4 & 12.844 & -5.680 & 1.068 & 1.009 & 0.836 & 4.610 & -3.693 & 11.999 & 1.286 & 1.647 & 0.929 \\
\hline \multirow[t]{4}{*}{6} & Lasa & 1 & 14.888 & 10.043 & - & - & - & - & - & 4.938 & 1.054 & 1.394 & 0.925 \\
\hline & & 2 & 19.672 & -5.352 & 422.923 & 2.210 & - & - & - & 4.882 & 1.014 & 1.289 & 0.937 \\
\hline & & 3 & 20.489 & -4.840 & 0.262 & - & - & - & - & 5.274 & 1.072 & 1.334 & 0.932 \\
\hline & & 4 & 19.733 & 1.016 & -2.076 & -0.146 & -5.290 & 0.868 & 6.940 & 4.003 & 0.824 & 1.083 & 0.956 \\
\hline \multirow[t]{4}{*}{7} & Kashi & 1 & 5.232 & 18.197 & - & - & - & - & - & 6.947 & 1.004 & 1.320 & 0.978 \\
\hline & & 2 & 15.141 & -8.867 & -373.907 & 20.295 & - & - & - & 6.354 & 0.919 & 1.201 & 0.982 \\
\hline & & 3 & 15.381 & -8.740 & 0.042 & - & - & - & - & 6.661 & 0.938 & 1.207 & 0.982 \\
\hline & & 4 & 15.343 & -0.608 & 2.951 & 2.570 & -8.771 & 0.999 & 6.337 & 5.618 & 0.844 & 1.126 & 0.984 \\
\hline \multirow[t]{4}{*}{8} & Tulufan & 1 & 4.286 & 19.412 & - & - & - & - & - & 6.392 & 0.905 & 1.208 & 0.984 \\
\hline & & 2 & 13.813 & -10.094 & -412.644 & 1.063 & - & - & - & 5.273 & 0.785 & 1.094 & 0.987 \\
\hline & & 3 & 15.112 & -9.286 & 0.158 & - & - & - & - & 7.513 & 0.956 & 1.226 & 0.983 \\
\hline & & 4 & 13.696 & 10.180 & 0.876 & 17.811 & 0.481 & 3.653 & 2.703 & 5.108 & 0.752 & 1.039 & 0.988 \\
\hline \multirow[t]{4}{*}{9} & Mengzi & 1 & 12.799 & 4.564 & - & - & - & - & - & 11.466 & 1.709 & 2.127 & 0.588 \\
\hline & & 2 & 14.911 & -2.862 & -435.726 & 0.431 & - & - & - & 9.627 & 1.437 & 1.789 & 0.733 \\
\hline & & 3 & 15.343 & -2.676 & 0.742 & - & - & - & - & 9.894 & 1.471 & 1.827 & 0.719 \\
\hline & & 4 & 15.332 & 2.497 & 0.942 & 5.678 & 1.005 & 2.260 & 2.492 & 9.103 & 1.348 & 1.660 & 0.776 \\
\hline
\end{tabular}

Another sine wave correlation used by Al-Salaymeh [27]:

$H=a_{0}+a_{1} \times \sin \left(\frac{2 \pi}{a_{2}} n+a_{3}\right)$

Kaplanis and Kaplani [28] suggested a cosine wave correlation:

$H=a_{0}+a_{1} \times \cos \left(\frac{2 \pi}{364} n+a_{2}\right)$

In addition, a new model in conjunction with a sine and cosine wave correlation is proposed and defined as follows:

$H=a_{0}+a_{1} \times \sin \left(\frac{2 \pi a_{2}}{365} n+a_{3}\right)+a_{4} \times \cos \left(\frac{2 \pi a_{5}}{365} n+a_{6}\right)$

Where $H$ is the daily global solar radiation and $n$ is the number of the day of year starting from January 1 . For the 1 st January, $n=1$, and for 31st December $n=365 . a_{0}, a_{1}, a_{2}, a_{3}, a_{4}, a_{5}$ and $a_{6}$ are the empirical coefficients.

\section{Performance evaluations}

In this study, the performance of the models is evaluated in terms of the mean absolute percentage error (MAPE), mean absolute bias error (MABE), root mean square error (RMSE) and correlation coefficients $(r)$. These error terms can be calculated using the following equations:
$\mathrm{MAPE}=\frac{1}{n} \sum_{i=1}^{n}\left|\frac{H_{c i}-H_{m i}}{H_{m i}} \times 100\right|$

$\mathrm{MABE}=\frac{1}{n} \sum_{i=1}^{n}\left|H_{c i}-H_{m i}\right|$

RMSE $=\sqrt{\frac{1}{n} \sum_{i=1}^{n}\left(H_{c i}-H_{m i}\right)^{2}}$

$r=\frac{\sum_{i=1}^{n}\left(H_{c i}-H_{c a}\right) \cdot\left(H_{m i}-H_{m a}\right)}{\sqrt{\left[\sum_{i=1}^{n}\left(H_{c i}-H_{c a}\right)^{2}\right] \cdot\left[\sum_{i=1}^{n}\left(H_{m i}-H_{m a}\right)^{2}\right]}}$

where $H_{c i}$ and $H_{m i}$ are the $i$ th calculated value and measured value, respectively; $H_{c a}$ and $H_{m a}$ are the average of the calculated and measured values, respectively.

\section{Results and discussion}

The performance of the above four models, Eqs. (1)-(4), are evaluated at nine meteorological stations over China, namely Minqin, Shantou, Leting, Harbin, Ganzhou, Lasa, Kashi, Tulufan and Mengzi, which represent geographical and climatic conditions of their regions suggested by Lam et al. [31].

According to MAPE, MABE, RMSE and $r$ as shown in Table 1, the proposed model, Eq. (4), has the best accuracy based on the measured data at nine stations, with the MAPE, MABE, RMSE and $r$ in 

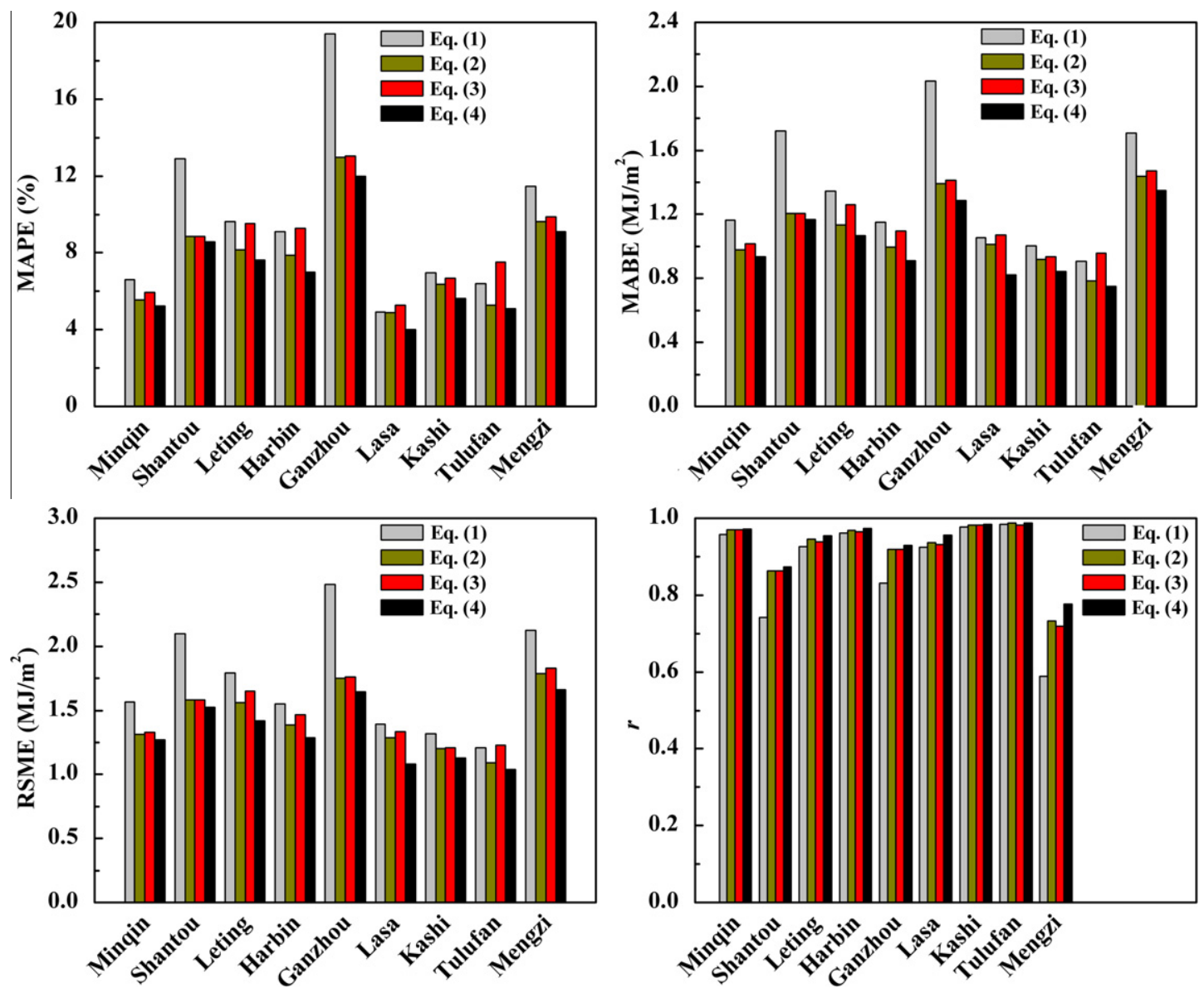

Fig. 2. Comparison between the MAPE, MABE, RSME and $r$ of Eqs. (1)-(4) at nine stations in China.

the range of $4.004-11.999 \%, 0.752-1.348 \mathrm{MJ} / \mathrm{m}^{2}, \quad 1.039-1.660$ $\mathrm{MJ} / \mathrm{m}^{2}$ and $0.776-0.988$, respectively. This indicates that we can obtain reasonably accurate data of daily global solar radiation from the proposed model. Eqs. (2) and (3) yield sound estimations, and the estimation differences among them are very slight, but their performance is second to Eq. (4); Eq. (1) yields relatively large errors with maximum MAPE value of $19.393 \%$ at Ganzhou and minimum $r$ value below 0.6 at Mengzi. To be obvious, the MAPE, MABE, RMSE and $r$ of the four models for the nine typical stations are shown in Fig. 2.

In terms of $r$, the stations with the best and worst value, i.e., Tulufan and Mengzi station are selected for further comparative investigation. Fig. 3 shows apparently that the performance of Eqs. (1)-(4) following the variation of the daily global solar radiation throughout the year at Tulufan station (Fig. 3a) is better than that at Mengzi station (Fig. 3b), mainly due to different weather conditions in these two regions, which can be seen apparently from the solar radiation variation in Fig. 3. The interest we focus is that the performance degradation of the four models according to the weather conditions is much different, and the minimum degradation of $r, 0.2$ (Table 1), is obtained by Eq. (4). This illustrates that Eq. (4) has better adaptability to the complicated weather conditions than the other models.

Overall evaluation, the relative performance of the four models at nine stations is that the Eq. (4) is best, followed by Eqs. (2) and (3), and Eq. (1) shows poor performance. So, for China, the daily global solar radiation can be estimated by the proposed model with better accuracy.

Based on the data at the other 70 stations, the regression coefficients of Eq. (4) and corresponding errors have been generated for each station, as shown in Table 2. The results showed that the regression coefficients of Eq. (4) are site dependent. For most of the stations, the best performance, based on MAPE, MABE, RMSE and $r$ is achieved by Eq. (4). The errors resulting from Eq. (4) for the 70 stations are such that the MAPE at about $77 \%$ of the stations does not go beyond $10 \%$ and has an average value of $7.960 \%$, the MABE lies between 0.737 and $1.417 \mathrm{MJ} / \mathrm{m}^{2}$, the RMSE stays well below $1.832 \mathrm{MJ} / \mathrm{m}^{2}$ and the mean value of $r$ at all stations is up to 0.937 . This result is considered acceptable.

\section{Conclusions}

Empirical modeling is an essential and economical tool for estimating solar radiation. A trigonometric model in conjunction with a sine and cosine wave for estimating daily global solar radiation is proposed in this study.

The model is compared with three existing models at nine representative stations of China by using statistical indicators such as the mean absolute percentage error (MAPE), mean absolute bias error (MABE), root mean square error (RMSE) and correlation coefficients $(r)$. It is found that the new model can be used for estimating daily values of global solar radiation with a higher accuracy and has good adaptability to highly variable weather conditions. Then the regression coefficients and errors of the proposed model are generated at the other 70 meteorological stations of China, and the statistical indicators are at acceptable levels.

The model is very simple, fast, effective and reliable, and estimations can be derived even by a pocket calculator without tedious inputting work for meteorological measurements. There- 

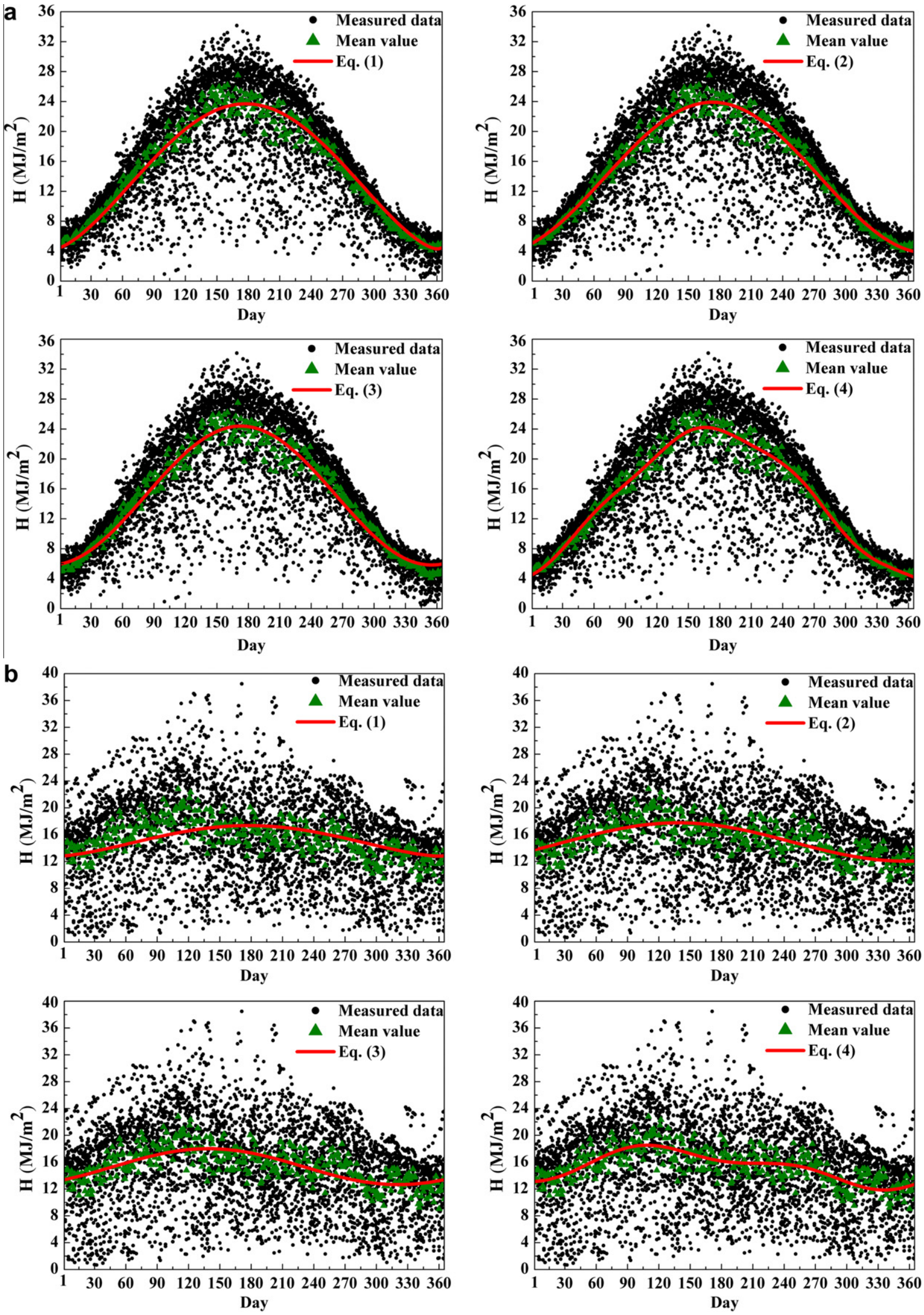

Fig. 3. Comparison between daily measured global solar radiation data and estimated values from Eqs. (1)-(4) at (a) Tulufan and (b) Mengzi station. 
Table 2

Regression coefficients of Eq. (4) and errors for the other 70 stations.

\begin{tabular}{|c|c|c|c|c|c|c|c|c|c|c|c|c|}
\hline \# & Location & $a_{0}$ & $a_{1}$ & $a_{2}$ & $a_{3}$ & $a_{4}$ & $a_{5}$ & $a_{6}$ & MAPE & MABE & RMSE & $r$ \\
\hline 1 & Beijing & 13.363 & -5.885 & 0.962 & 2.045 & -1.035 & 2.177 & -0.874 & 7.909 & 1.068 & 1.422 & 0.949 \\
\hline 2 & Fuzhou & 12.596 & -4.928 & 1.059 & 1.128 & 0.700 & 2.409 & 3.511 & 12.209 & 1.375 & 1.761 & 0.896 \\
\hline 3 & Dunhuang & 16.318 & -0.589 & 2.528 & -0.583 & 8.827 & 0.873 & 9.967 & 4.970 & 0.853 & 1.131 & 0.982 \\
\hline 4 & Jiuquan & 16.439 & -0.586 & 2.297 & -0.042 & 8.136 & 0.952 & -2.807 & 5.052 & 0.865 & 1.182 & 0.979 \\
\hline 5 & Lanzhou & 13.495 & -0.348 & 12.383 & -2.566 & -7.158 & 0.938 & 0.422 & 8.665 & 1.236 & 1.677 & 0.946 \\
\hline 6 & Guangzhou & 11.526 & -3.175 & 1.018 & 0.737 & -0.646 & 4.758 & -0.893 & 10.330 & 1.095 & 1.357 & 0.860 \\
\hline 7 & Beihai & 14.362 & 1.269 & 2.150 & 9.313 & -4.461 & 1.030 & -0.516 & 10.513 & 1.395 & 1.727 & 0.889 \\
\hline 8 & Guilin & 11.719 & -0.874 & 4.835 & 0.755 & 5.520 & 1.008 & 2.569 & 13.165 & 1.315 & 1.656 & 0.922 \\
\hline 9 & Nanning & 11.863 & -0.784 & 2.780 & -1.589 & -5.193 & -0.895 & 0.110 & 11.098 & 1.200 & 1.495 & 0.924 \\
\hline 10 & Haikou & 13.500 & -0.607 & 6.006 & -1.253 & -5.465 & 0.921 & 0.204 & 10.224 & 1.277 & 1.612 & 0.917 \\
\hline 11 & Sanya & 16.607 & -3.086 & -1.035 & 7.722 & 0.820 & 2.250 & 1.651 & 6.741 & 1.087 & 1.415 & 0.859 \\
\hline 12 & Xisha & 17.391 & -5.315 & 0.813 & 2.588 & -0.911 & 2.011 & -0.195 & 7.133 & 1.259 & 1.599 & 0.909 \\
\hline 13 & Gushi & 11.860 & -0.604 & 6.830 & 5.535 & 5.785 & 0.888 & -2.637 & 10.076 & 1.179 & 1.480 & 0.933 \\
\hline 14 & Nanyang & 11.427 & -5.820 & 0.883 & -4.174 & 0.396 & -13.448 & 20.051 & 9.321 & 1.101 & 1.441 & 0.935 \\
\hline 15 & Zhengzhou & 12.865 & 5.718 & 0.973 & -1.182 & -0.637 & 2.134 & -1.083 & 8.785 & 1.079 & 1.395 & 0.946 \\
\hline 16 & Fuyu & 12.844 & -8.946 & -0.869 & 0.955 & 0.596 & 3.746 & -3.723 & 6.261 & 0.911 & 1.306 & 0.975 \\
\hline 17 & Heihe & 11.883 & 0.643 & 3.930 & -3.289 & 8.540 & 0.905 & 3.677 & 6.747 & 0.864 & 1.235 & 0.978 \\
\hline 18 & Jiamusi & 11.342 & -0.613 & -3.854 & 2.920 & 7.899 & 0.878 & 3.708 & 6.924 & 0.888 & 1.257 & 0.972 \\
\hline 19 & Mohe & 11.247 & -9.066 & 0.910 & 2.106 & -0.623 & 4.104 & 4.191 & 9.115 & 1.063 & 1.510 & 0.971 \\
\hline 20 & Changsha & 10.963 & 0.715 & -4.550 & -1.109 & 5.555 & 1.045 & 9.033 & 13.629 & 1.270 & 1.622 & 0.928 \\
\hline 21 & Changning & 11.033 & -0.875 & 4.784 & 0.617 & 5.599 & -1.078 & 3.738 & 14.821 & 1.329 & 1.696 & 0.924 \\
\hline 22 & Jishou & 10.280 & 5.190 & 1.067 & -2.036 & 1.035 & -2.422 & 3.462 & 13.952 & 1.217 & 1.565 & 0.928 \\
\hline 23 & Changchun & 11.714 & 8.179 & 0.799 & -7.021 & 0.826 & 3.678 & -3.666 & 7.847 & 1.086 & 1.476 & 0.958 \\
\hline 24 & Yanji & 10.861 & 7.892 & 0.757 & 5.639 & 0.572 & 3.871 & 1.562 & 7.682 & 0.984 & 1.318 & 0.959 \\
\hline 25 & Lusi & 10.926 & -0.980 & 4.700 & -6.236 & -6.979 & 0.688 & 7.311 & 10.553 & 1.371 & 1.747 & 0.900 \\
\hline 26 & Nanjing & 10.669 & -6.172 & 0.766 & 8.674 & -0.632 & 6.937 & -2.320 & 9.994 & 1.194 & 1.550 & 0.916 \\
\hline 27 & Chaoyang & 13.687 & -0.932 & 2.265 & 6.930 & 6.727 & 0.938 & -2.697 & 7.134 & 0.992 & 1.342 & 0.963 \\
\hline 28 & Dalian & 13.808 & 1.206 & -2.301 & 5.943 & 6.326 & 0.964 & -2.719 & 8.830 & 1.198 & 1.607 & 0.946 \\
\hline 29 & Shenyang & 12.961 & 0.940 & 2.255 & 9.979 & 6.509 & 0.921 & 9.914 & 8.999 & 1.172 & 1.530 & 0.949 \\
\hline 30 & Dongsheng & 15.655 & 0.706 & 2.112 & -2.603 & -7.337 & 0.960 & 0.411 & 5.699 & 0.921 & 1.264 & 0.971 \\
\hline 31 & Ejinaqi & 17.371 & 0.607 & 2.241 & 3.466 & -9.194 & 0.949 & 0.340 & 4.000 & 0.737 & 1.025 & 0.988 \\
\hline 32 & Erlianhaote & 16.835 & 8.652 & 0.978 & -1.258 & 0.852 & 2.118 & -3.565 & 4.282 & 0.765 & 1.070 & 0.985 \\
\hline 33 & Hailaer & 12.433 & -8.725 & -0.904 & -5.251 & 0.549 & 3.991 & 1.690 & 6.439 & 0.849 & 1.220 & 0.979 \\
\hline 34 & Hailiutu & 16.474 & -0.721 & 2.122 & 6.865 & 8.343 & 0.965 & 3.465 & 5.558 & 0.937 & 1.216 & 0.979 \\
\hline 35 & Suolun & 14.358 & 1.158 & 2.090 & -1.441 & -7.467 & 0.975 & 0.299 & 5.556 & 0.860 & 1.276 & 0.973 \\
\hline 36 & Tongliao & 13.791 & -0.792 & 2.173 & 0.878 & 7.127 & 0.938 & 3.602 & 5.880 & 0.856 & 1.195 & 0.973 \\
\hline 37 & Xilinhaote & 14.887 & 0.589 & 2.277 & -2.340 & 7.882 & 0.936 & -2.759 & 5.200 & 0.825 & 1.193 & 0.977 \\
\hline 38 & Guyuan & 15.585 & 5.993 & 1.003 & -1.236 & 0.425 & 6.983 & 1.937 & 7.079 & 1.098 & 1.447 & 0.947 \\
\hline 39 & Yinchuan & 15.112 & -0.623 & 1.848 & 0.565 & -7.820 & -0.903 & 5.733 & 5.975 & 0.966 & 1.309 & 0.970 \\
\hline 40 & Gangcha & 17.716 & 1.465 & 1.779 & -0.896 & 6.074 & 1.020 & -2.905 & 5.624 & 1.038 & 1.449 & 0.943 \\
\hline 41 & Geermu & 18.553 & 7.834 & 0.958 & -1.264 & 0.928 & 2.076 & 2.725 & 4.351 & 0.846 & 1.132 & 0.980 \\
\hline 42 & Guoluo & 15.783 & 0.999 & 3.082 & 2.754 & 6.163 & -0.747 & 2.126 & 6.286 & 1.087 & 1.397 & 0.929 \\
\hline 43 & Xining & 14.147 & 6.856 & 0.811 & -0.787 & -0.947 & 1.322 & 0.275 & 6.363 & 1.012 & 1.396 & 0.954 \\
\hline 44 & Yushu & 14.503 & -0.720 & 2.958 & -0.153 & -7.465 & 0.721 & 1.028 & 5.614 & 0.957 & 1.230 & 0.956 \\
\hline 45 & Fushan & 14.077 & 6.240 & 0.956 & -1.107 & 1.228 & 2.202 & 2.136 & 8.060 & 1.115 & 1.449 & 0.953 \\
\hline 46 & Jinan & 13.091 & 1.166 & 2.204 & -9.065 & -5.781 & 0.992 & 0.340 & 8.322 & 1.052 & 1.338 & 0.955 \\
\hline 47 & Juxian & 13.713 & -5.633 & 0.983 & 1.951 & -1.108 & 2.191 & -0.983 & 8.452 & 1.120 & 1.422 & 0.946 \\
\hline 48 & Datong & 14.471 & 0.933 & 2.018 & 4.374 & -7.348 & 0.985 & 0.310 & 5.873 & 0.879 & 1.232 & 0.973 \\
\hline 49 & Houma & 12.504 & -0.419 & -18.143 & -19.406 & 6.490 & 0.955 & 3.563 & 8.014 & 1.003 & 1.320 & 0.959 \\
\hline 50 & Taiyuan & 13.043 & 6.262 & -0.980 & -8.225 & 0.681 & 1.966 & -3.240 & 7.069 & 0.923 & 1.263 & 0.961 \\
\hline 51 & Ankang & 11.576 & 0.928 & 2.160 & -0.491 & 6.237 & 1.007 & 3.228 & 11.604 & 1.236 & 1.568 & 0.944 \\
\hline 52 & Yanan & 12.828 & -6.816 & 0.832 & 2.327 & -1.020 & 1.587 & -0.816 & 7.804 & 1.089 & 1.440 & 0.953 \\
\hline 53 & Chengdu & 8.273 & -0.691 & 3.357 & -1.969 & 5.398 & 0.910 & 9.877 & 15.427 & 1.177 & 1.498 & 0.922 \\
\hline 54 & Emeishan & 13.409 & -2.431 & 1.003 & 2.416 & -0.749 & 2.253 & -0.194 & 10.132 & 1.315 & 1.663 & 0.751 \\
\hline 55 & Ganzi & 18.298 & -5.323 & 1.060 & 1.641 & 1.406 & 1.694 & -2.085 & 6.250 & 1.148 & 1.517 & 0.915 \\
\hline 56 & Hongyuan & 15.561 & 4.532 & 0.783 & -0.615 & 1.060 & 2.973 & 1.530 & 7.600 & 1.274 & 1.662 & 0.857 \\
\hline 57 & Mianyang & 9.227 & 5.708 & -0.910 & 4.263 & -0.796 & 3.299 & -3.119 & 12.141 & 1.077 & 1.353 & 0.942 \\
\hline 58 & Panzhihua & 15.416 & 1.302 & 1.866 & 5.286 & 3.992 & 0.986 & -2.446 & 6.532 & 1.004 & 1.346 & 0.902 \\
\hline 59 & Tianjin & 13.111 & -0.834 & 2.220 & 0.641 & -6.062 & 0.963 & 6.708 & 8.788 & 1.128 & 1.505 & 0.946 \\
\hline 60 & Changdu & 16.248 & -0.420 & 6.825 & -7.125 & -4.753 & 0.881 & 6.818 & 5.509 & 0.930 & 1.209 & 0.933 \\
\hline 61 & Naqu & 17.598 & 0.878 & 1.851 & 4.207 & 5.521 & 0.760 & 4.089 & 4.888 & 0.941 & 1.244 & 0.930 \\
\hline 62 & Akesu & 14.606 & 8.605 & 0.952 & -1.336 & -0.443 & 2.909 & 1.408 & 5.288 & 0.791 & 1.077 & 0.984 \\
\hline 63 & Hami & 16.390 & -0.592 & -2.341 & 3.102 & -9.615 & 0.938 & 12.972 & 4.485 & 0.772 & 1.073 & 0.987 \\
\hline 64 & Hetian & 14.254 & -7.968 & 0.814 & 2.263 & -0.758 & 2.208 & 4.346 & 5.715 & 0.866 & 1.136 & 0.974 \\
\hline 65 & Tacheng & 14.691 & -0.669 & 3.476 & 8.532 & 10.313 & 0.945 & 3.477 & 6.347 & 0.891 & 1.209 & 0.986 \\
\hline 66 & Yanqi & 14.292 & -0.565 & 2.353 & 6.144 & -9.477 & 0.889 & 0.480 & 5.303 & 0.798 & 1.079 & 0.986 \\
\hline 67 & Jinghong & 15.106 & -1.203 & 2.297 & 6.715 & 2.022 & 0.784 & -1.852 & 7.350 & 1.104 & 1.399 & 0.778 \\
\hline 68 & Kunming & 14.436 & 2.927 & 0.976 & -0.183 & 1.439 & 2.308 & -3.984 & 9.191 & 1.227 & 1.588 & 0.835 \\
\hline 69 & Lijiang & 16.813 & -2.878 & 0.979 & 2.546 & -1.015 & 1.787 & 0.232 & 6.358 & 1.068 & 1.412 & 0.826 \\
\hline 70 & Hongjia & 12.783 & -0.991 & 4.325 & 2.025 & 5.174 & 0.952 & 3.088 & 12.104 & 1.417 & 1.832 & 0.893 \\
\hline
\end{tabular}

fore, the proposed model is recommended for estimating the daily global solar radiation in areas where the radiation data is missing or not available and predicting yearly variations of daily global solar radiation for a specific location, which helps in evaluating the long-term performances of solar energy systems. 


\section{Acknowledgements}

The authors would like to thank the National Meteorological Information Centre (NMIC), China Meteorological Administration for its data supports.

\section{References}

[1] Guo LJ, Zhao L, Jing DW, Lu YJ, Yang HH, Bai BF, Zhang XM, Ma LJ, Wu XM. Solar hydrogen production and its development in China. Energy 2009;34(9): 1073-90.

[2] El-Sebaii AA, Al-Hazmi FS, Al-Ghamdi AA, Yaghmour SJ. Global, direct and diffuse solar radiation on horizontal and tilted surfaces in Jeddah, Saudi Arabia. Appl Energy 2010;87(2):568-76.

[3] National Bureau of Statistics of China. China statistical yearbook 2008; 2008 <http://www.stats.gov.cn/tjsj/ndsj/2008/indexch.htm> [accessed 15/12/2009].

[4] Zhou J, Wu YZ, Yan G. General formula for estimation of monthly average daily global solar radiation in China. Energy Convers Manage 2005;46(2):257-68.

[5] Ångström A. Solar and terrestrial radiation. Quart J Roy Meteorol Soc 1924;50(210):121-5.

[6] Prescott JA. Evaporation from a water surface in relation to solar radiation. Trans Roy Soc Aust 1940;64:114-25.

[7] Akinoglu BG. A review of sunshine-based models used to estimate monthly average global solar radiation. Renew Energy 1991;1(3-4):479-97.

[8] Bakirci K. Models of solar radiation with hours of bright sunshine: a review. Renew Sustain Energy Rev 2009;13(9):2580-8.

[9] Bristow KL, Campbell GS. On the relationship between incoming solar radiation and daily maximum and minimum temperature. Agric Forest Meteorol 1984;31(2):159-66.

[10] Hargreaves GH, Samani ZA. Estimating potential evapotranspiration. J Irrig Drain Div 1982;108(3):225-30.

[11] Liu XY, Mei XR, Li YZ, Wang QS, Jensen JR, Zhang YQ, Porter JR. Evaluation of temperature-based global solar radiation models in China. Agric Forest Meteorol 2009;149(9):1433-46.

[12] Badescu V. A new kind of cloudy sky model to compute instantaneous values of diffuse and global solar irradiance. Theor Appl Climatol 2002;72(1-2): 127-36.

[13] Gul M, Muneer T, Kambezidis H. Models for obtaining solar radiation from other meteorological data. Sol Energy 1998;64(1-3):99-108.
[14] Lam JC, Li DHW. Correlation analysis of solar radiation and cloud cover. Int J Ambient Energy 1998;19(4):187-98.

[15] Thornton PE, Running SW. An improved algorithm for estimating incident daily solar radiation from measurements of temperature, humidity, and precipitation. Agric Forest Meteorol 1999;93(4):211-28.

[16] Winslow JC, Hunt Jr ER, Piper SC. A globally applicable model of daily solar irradiance estimated from air temperature and precipitation data. Ecol Modell 2001;143(3):227-43.

[17] Trabeaa AA, Shaltou MAM. Correlation of global solar radiation with meteorological parameters over Egypt. Renew Energy 2000;21(2):297-308.

[18] Mubiru J, Karume K, Majaliwa M, Banda EJKB, Otiti T. Interpolating methods for solar radiation in Uganda. Theor Appl Climatol 2007;88(3-4):259-63.

[19] Janjai S, Pankaew P, Laksanaboonsong J. A model for calculating hourly global solar radiation from satellite data in the tropics. Appl Energy 2009;86(9):1450-7.

[20] Zaharim A, Razali AM, Gim TP, Sopian K. Time series analysis of solar radiation data in the tropics. Eur J Sci Res 2009;25(4):672-8.

[21] Jain PK, Lungu EM. Stochastic models for sunshine duration and solar irradiation. Renew Energy 2002;27(2):197-209.

[22] Gueymard C. Parameterized transmittance model for direct beam and circumsolar spectral irradiance. Sol Energy 2001;71(5):325-46.

[23] Senkal O, Kuleli T. Estimation of solar radiation over Turkey using artificial neural network and satellite data. Appl Energy 2009;86(7-8):1222-8.

[24] Fadare DA. Modelling of solar energy potential in Nigeria using an artificial neural network model. Appl Energy 2009;86(9):1410-22.

[25] Bulut H. Generation of typical solar radiation data for Istanbul, Turkey. Int J Energy Res 2003;27(9):847-55.

[26] Bulut H, Büyükalaca O. Simple model for the generation of daily global solarradiation data in Turkey. Appl Energy 2007;84(5):477-91.

[27] Al-Salaymeh A. Model for the prediction of global daily solar radiation on horizontal surfaces for Amman city. Emirates J Eng Res 2006;11(1):49-56.

[28] Kaplanis S, Kaplani E. A model to predict expected mean and stochastic hourly global solar radiation $I(h ; n j)$ values. Renew Energy 2007;32(8):1414-25.

[29] Jiang YN. Estimation of monthly mean daily diffuse radiation in China. Appl Energy 2009;86(9):1458-64.

[30] Jiang YN. Computation of monthly mean daily global solar radiation in China using artificial neural networks and comparison with other empirical models. Energy 2009;34(9):1276-83.

[31] Lam JC, Wan KKW, Lau CCS, Yang L. Climatic influences on solar modelling in China. Renew Energy 2008;33(7):1591-604.

[32] Zeroual A, Ankrim M, Wilkinson AJ. Stochastic modelling of daily global solar radiation measured in Marrakesh, Morocco. Renew Energy 1995;6(7):787-93. 